\title{
IMIGRANTES E REFUGIADOS NO MERCADO DE TRABALHO BRASILEIRO: UMA REVISÃO BIBLIOGRÁFICA A PARTIR DAS CONTRIBUIÇÕES DA PSICOLOGIA DO TRABALHO
}

\section{ARTIGO DE REVISÃO}

FALCI, Gabrielle Xavier de Souza ${ }^{1}$

SOUZA, Narciane Bertolaccini de ${ }^{2}$

SCATOLIN, Henrique Guilherme ${ }^{3}$

FALCI, Gabrielle Xavier de Souza. SOUZA, Narciane Bertolaccini de. SCATOLIN, Henrique Guilherme. Imigrantes e refugiados no mercado de trabalho brasileiro: Uma revisão bibliográfica a partir das contribuições da Psicologia do Trabalho. Revista Científica Multidisciplinar Núcleo do Conhecimento. Ano 05, Ed. 11, Vol. 22, pp. 135-151. Novembro de 2020. ISSN: 2448-0959, Link de acesso: https://www.nucleodoconhecimento.com.br/psicologia/imigrantes-erefugiados

\section{RESUMO}

Tendo em vista o mercado de trabalho brasileiro e suas diversas formas de existir, o presente artigo se propôs a pensar na inserção de imigrantes e refugiados neste sistema e, desta forma, investigar e explorar mais este movimento social mundial, uma vez que há pouco estudo deste fenômeno, assim como seus impactos no campo da Psicologia Organizacional e do Trabalho. Isto posto, este artigo objetiva compreender a real motivação dos estrangeiros na escolha do Brasil como um país atraente para o refúgio e, também, analisar o processo de inserção destes sujeitos no mercado de

\footnotetext{
${ }^{1}$ Pós-graduação em Psicologia Organizacional e do Trabalho.

2 Pós-graduação em Psicologia Organizacional e do Trabalho.

${ }^{3}$ Orientador. Doutor em Psicologia Clínica.
} 
trabalho brasileiro. O uso da pesquisa bibliográfica permitiu a busca, a leitura, e a análise dos textos que abordavam a questão dos imigrantes e dos refugiados. A justificativa para este estudo é voltada para uma análise crítica interpondo a motivação dos imigrantes e refugiados em se estabelecer no Brasil para viver e o preparo do país em inserir estes sujeitos no mercado de trabalho. Observou-se que os países vizinhos e fronteiriços ao Brasil, dentre os quais alguns propiciam um estado de vulnerabilidade para os seus residentes, seja no contexto de guerras, opressões políticas, fome ou miséria, promovem diretamente a fuga de imigrantes e refugiados para o Brasil. Estes sujeitos buscam no país um novo espaço para a ressignificação da identidade a partir de um novo trabalho e um possível recomeço.

Palavras-chave: Refugiados, imigrantes, trabalho.

\section{INTRODUÇÃO}

A presente pesquisa realizou uma análise bibliográfica sobre a inserção de imigrantes e refugiados no mercado de trabalho. Este estudo buscou na literatura o real motivo pelo qual o Brasil acaba sendo escolhido como destino de fuga, e como se dá à inserção no mercado de trabalho dos sujeitos que estão em processo de imigração ou de refúgio.

Observa-se a vasta produção de materiais científicos que abordam a temática a partir de diversos pontos, inclusive nas mídias sociais; entretanto, quando fala-se sobre imigrantes/ e ou refugiados, nota-se a precariedade da eficiência das políticas públicas com relação aos cuidados desses sujeitos, inclusive no campo do mercado de trabalho, bem como não se exploram muito a motivação do Brasil como destino de refúgio e também para uma melhor qualidade de vida dos mesmos. Corroborando com esta perspectiva, Etcheverry (2013) denomina de mediadores os órgãos e instituições que auxiliam os imigrantes, bem como expressa a complexidade de ter o fenômeno da migração sendo notado em partes e áreas com grande visibilidade, enquanto que em outras áreas passa na invisibilidade. 
O que leva pessoas a saírem de seu país de origem, e se mudarem para outras nações como imigrante ou como refugiado, muitas vezes, é devido a crises econômicas, sociais, de guerra, fome ou motivados pela esperança de um local mais propício a realização emocional de felicidade, conforme Gondim (2013). Dentro deste contexto, Martin; Goldenberg e Silveira ao mencionar Zimmerman; Kiss e Hossain (2011), completam a ideia de mudança de país por questões econômicas, políticas e ambientais, expondo esses sujeitos a diversas fragilidades durante o processo migratório.

Entre as diversas consequências decorrentes dessa fragilidade, pode estar relacionada com o aprimoramento da identidade como processo contínuo do sujeito. Sobre isso, Bauman (2005) discorre sobre a identidade como algo oriundo de uma crise do pertencimento.

Segundo Martin, Goldenberg e Silveira (2018), um aspecto importante a ser destacado é a atenção prestada aos imigrantes e refugiados na cidade de São Paulo, uma das cidades que mais recebe estrangeiros no Brasil, como aponta Gondim et al. (2013), inclusive com a elaboração do conselho municipal que atende demandas relacionadas à saúde/doença promovendo um cuidado voltado as necessidades do grupo em questão. Outro ponto a ser abordado refere-se ao que motiva imigrantes/refugiados de países da América do Sul, vizinhos do Brasil, encaminharem-se para territórios brasileiros em busca de novas oportunidades, comportamento este que se destaca por seu fluxo migratório (CARNEIRO, 2017).

A relevância proposta nesta pesquisa, foi de entender a questão da diversidade multicultural no âmbito do trabalho nos dias atuais, visto que o fenômeno da imigração/refúgio se dá desde tempos remotos. É possível supor que há uma crítica elevada sobre a inserção destes sujeitos no mercado, seja por uma aceitação solidária ou por uma necessidade de mercado de trabalho. Diante disso, com o contexto apresentado, há uma dificuldade de adaptação e assistência a estes sujeitos estrangeiros, pois o cenário brasileiro acaba não tendo um preparo de aceitação da subjetividade dos próprios nativos. O preconceito que ocorre em relação aos estrangeiros que são imigrantes e/ou refugiados é tido como um dos principais fatores 
que dificultam a inserção destes sujeitos no meio social e também no mercado de trabalho (MOREIRA, 2010).

Agregando valor as pontuações anteriores, discute-se ao longo do artigo a questão da ilegalidade no país, que leva a contratação destes imigrantes com algumas características, como por exemplo, mão de obra com baixos salários, pertinente à exoneração de impostos, e postos de trabalhos que os habitantes nacionais recusam (ETCHEVERRY, 2013).

Diante do que foi apresentado até o momento, o presente trabalho tratou sobre a temática da imigração e de refugiados a partir de literaturas já existentes com a intenção de encontrar informações que apresentassem características de imigrantes e refugiados que buscam pelo Brasil como um novo espaço de morada e, diante dessas informações, entender quais os motivos que tornam terras brasileiras tão atrativas na visão desses sujeitos.

Desta forma, no decorrer do trabalho, será apresentado a diferença conceitual das palavras "emigração", "imigração", "migração" e "refúgio", cujas definições são de extrema relevância para a distinção e compreensão das mesmas, como forma de evitar equívocos de interpretação.

\section{METODOLOGIA}

A presente pesquisa foi realizada com base em materiais já existentes, o que torna o artigo uma produção de pesquisa bibliográfica, que do ponto de vista de Cervo (2007) é o tipo de pesquisa que vai em busca de respostas para um determinado problema através de referenciais teóricos já publicados em forma de teses, livros, artigos e dissertações. Este mesmo autor aponta que a pesquisa bibliográfica pode ser realizada de duas formas, sendo descritiva ou experimental (CERVO, 2007).

De acordo com Oliveira (1997), a pesquisa bibliográfica tem como objetivo explorar as diversas formas de contribuição científica dos múltiplos assuntos e fenômenos que foram estudados. Reforçando a importância da pesquisa bibliográfica, Gil (2010) 
aponta a amplitude de possibilidades de fenômenos que podem ser investigados por meio de materiais científicos já existentes, possibilitando uma vantagem ao pesquisador em otimizar o tempo e o espaço de atuação da pesquisa, uma vez que ele tem um único local como fonte de pesquisa, tal qual uma biblioteca física ou digital. Ainda segundo o autor, essa facilidade precisa ser bem estudada e aproveitada para que não se multiplique equívocos de dados apresentados nos materiais pesquisados (GIL, 2010).

Considerando os aspectos acima, o referido trabalho pode ser considerado como pesquisa descritiva, que para Cervo (2007) pode ser denominada como aquela que realiza correlações e análises de um fenômeno, sem que haja a manipulação de variáveis, na tentativa de compreender aspectos das relações humanas. É um tipo de pesquisa muito utilizada na área de ciências humanas e que pode ter formas diferenciadas ao ser explorada (CERVO, 2007).

Os descritores utilizados e que auxiliaram na busca por materiais foram: "imigrantes no Brasil", "imigrantes no mercado de trabalho", "refugiados e o trabalho", "chegada dos portugueses no Brasil artigo" e "mercado de trabalho no Brasil para imigrantes". Vale lembrar que, antes do tema ser escolhido para pesquisa, foi realizada uma busca de materiais na base de dados Scielo, para se ter um norte de como estava a produção de pesquisas na área.

Referente ao descritor "imigrantes no Brasil", ao ser digitado na base de dados Scielo, foi filtrado um total 166 materiais, sendo que, apenas 5 foram selecionados para leitura. Com o descritor "imigrantes no mercado de trabalho Scielo", por conta da dificuldade em encontrar descritores que filtrassem artigos para a pesquisa, optou-se por utilizar o referido descritor na barra de pesquisa do Google, que filtrou 138.000 materiais e, selecionou-se apenas 6 artigos científicos.

Por fim, e não menos importante, utilizou-se o descritor "refugiados e o trabalho" na base de dados da Scielo, que consistiu em 32 materiais filtrados e, 6 artigos foram selecionados para leitura. Para a realização da breve retomada histórica dos imigrantes e refugiados, houve a necessidade de realizar uma nova busca nas 
plataformas de dados, para isso, foi utilizado o próprio Google como ferramenta, sendo que, o descritor utilizado foi "chegada dos portugueses no Brasil artigo", foram localizados 9.070 .000 resultados, 2 artigos selecionados e apenas 1 material foi utilizado para a construção do trabalho.

No decorrer do desenvolvimento da pesquisa, utilizou-se o descritor "mercado de trabalho no Brasil para imigrantes", para acrescentar novos conteúdos na apresentação da inserção dos imigrantes no mercado de trabalho. Ao ser digitado no Scielo, foram encontrados 9 artigos, destes, 2 foram utilizados. O mesmo descritor foi utilizado na plataforma do Google que encontrou aproximadamente 9.580.000 resultados, sendo utilizado apenas 1 na fundamentação.

Também foi utilizado 1 livro para discutir sobre identidade e 1 dicionário para a apresentação de significados. Os materiais selecionados para análise, consistem em publicações que foram realizadas entre período de 2009 à 2019.

Os descritores que foram excluídos são: "imigrante e refugiado diferença"; "significados imigrantes e refugiados" e "diferença entre refugiado e imigrante".

\section{FUNDAMENTAÇÃO TEÓRICA}

Antes de qualquer discussão e reflexão, é importante ressaltar, neste momento, as diferenças existentes entre as seguintes palavras: emigração, imigração, migração e refúgio. São palavras recorrentes em materiais científicos e que trazem significados diferentes. Diante do tema estudado, entende-se a necessidade de elucidar a diferenciação entre os significados destes conceitos.

De acordo com o dicionário Houaiss (2010), emigração se refere a "1 saída espontânea de um país; expatriação $\cup$ imigração 2 movimentação de uma para outra região dentro de um mesmo país 3 conjunto de indivíduos que emigram cf. Migração" (p.286). Sobre imigração, significa "1 entrada de estrangeiros em um país 2 estabelecimento de indivíduos em cidades, estados ou região de seu próprio país, que não a sua de origem 3 conjunto de indivíduos que imigram cf. migração e emigração 
4 o fluxo desses indivíduos" (p.420). Já a palavra migração relaciona-se ao "1 movimento de entrada ou saída de indivíduos em países diferentes ou mesmo dentro de um mesmo país cf. emigração e imigração 2 viagem periódica de animais de uma região para outra, ger. por questões ambientais" (p.521). Por fim, refúgio vem ser definido como "1 lugar para o qual se foge a fim de escapar a um perigo 2 fig. o que serve de amparo, consolo<a música era seu r. $>3$ esconderijo <o r. dos ladrões era na mata> refugiado adj.s.m.- refugiar-se v.pron" (HOUAISS, 2010, p.665).

No Brasil, o Ministério da Justiça e Segurança Pública do Governo Federal conta com - CONARE (Comitê Nacional para Refugiados, 2019) para determinar o reconhecimento de refugiados no Brasil, tendo seus conhecimentos descritos no art. 12 da Lei no 9.474, de 22 de julho de 1997. O comitê é composto por representantes governamentais e não-governamentais, como aponta o site do Ministério da Justiça e Segurança Pública:

Pelo governo, fazem parte do Conare o Ministério da Justiça e Segurança Pública (MJ - presidência), o Ministério das Relações Exteriores (MRE), o Ministério da Saúde (MS), o Ministério da Educação (MEC), o Ministério da Economia (ME), e a Polícia Federal (PF). Os atuais representantes da sociedade civil (titular e suplente, respectivamente) são da Cáritas Arquidiocesanas do Rio de Janeiro e de São Paulo. (CONARE, 2019).

Refletindo sobre aspectos que envolvem refúgio e imigração, cabe pensar e resgatar um ponto histórico muito importante para o Brasil, país que foi descoberto e colonizado por europeus, mas que de forma detalhada e com aprofundamento histórico, pode ser entendido como um processo que envolveu imigrantes e refugiados, que buscavam se reinventar e se abrigarem em terras desconhecidas.

Neste momento, cabe realizar uma breve retomada histórica sobre a chegada de imigrantes/refugiados no Brasil, que se inicia no ano de $1.500 \mathrm{com}$ a expansão do mercantilismo. Com o descobrimento do Brasil por Pedro Álvares Cabral, os portugueses carregados de intenções para expansão de territórios para seus comércios e especiarias, passaram a navegar pelo Oceano-Atlântico, até a chegada no Brasil (COSTA e FARIAS, 2009). 
De acordo com Costa e Farias (2009), os portugueses que chegaram até o Brasil no ano de 1.500, tinham interesses voltados para o comércio de especiarias e também pela busca de metais preciosos. Entretanto, as terras que hoje chamamos de Brasil, antes de sua descoberta e colonização, eram terras habitadas por indígenas com suas próprias "dinâmicas socioespaciais", causando então um grande e impetuoso choque cultural, marcada pela exploração dos europeus (COSTA e FARIAS, 2009).

Frente a esse contexto histórico do país, entender o que motiva ou as situações oriundas que fizeram uma pessoa tomar a decisão de sair de seu país, seja sozinho ou com sua família, para outra nação, é importante para contextualizar e traçar estratégias que auxiliem estes sujeitos a se adaptarem, inclusive no campo de trabalho. Segundo Gondim et al. (2013) a explicação para o fenômeno migratório é desde tempos antigos, podendo ser motivado pela fome, violência, perseguições políticas somadas a um desejo e esperança de melhora de vida.

O aumento da entrada de imigrantes no Brasil, por motivos econômicos ou de trabalho, também é apresentado pelos autores ao citar dados do Ministério do Trabalho e emprego do Brasil:

... Pelos dados da Coordenação geral de imigração (CGig)do Ministério do Trabalho e Emprego do Brasil (Ministério do Trabalho e Emprego do Brasil [MTE],2011, o número de autorização concedida a estrangeiros para trabalharem no país saltou de 29.488, em 2007 para 56.006 em 2010. (GONDIM et al, 2013).

Os autores Truzzi e Monsma (2018) também levantam um aspecto relevante, que aponta alguns motivos que atraem migrantes e refugiados para a América Latina. Mesmo sendo uma área com muitos registros de homicídio e criminalidade, ao mesmo tempo torna-se um espaço acolhedor por ter características diversas em termos culturais e raciais, apresentando baixos índices de guerras internacionais e civis e, qualquer outro tipo de violência coletiva (TRUZZI e MONSMA, 2018).

O trabalho, como se sabe, tem papel importante na elaboração e validação de subjetividade e autoestima do ser humano, sendo este um aspecto importante na concepção de sua identidade. O trabalho, no que tange a problemática da migração e 
dos refugiados, pode ser visto como uma ferramenta para a ressignificação de sua identidade e de seu sentimento de pertencimento no mundo. Sobre isto, podemos citar:

[...] Tornamo-nos conscientes de que "o pertencimento e a "identidade" não têm solidez de uma rocha, não são garantidos para toda a vida, são bastante negociáveis e revogáveis, e de que as decisões que o próprio individuo toma, os caminhos que percorre, a maneira como age - e a determinação de se manter firme a tudo isso - são fatores cruciais tanto para o" pertencimento" quanto para a "identidade". Em outras palavras, a idéia de "ter uma identidade" não vai ocorrer às pessoas enquanto o "pertencimento" continuar sendo seu destino, uma condição sem alternativa (BAUMAN, 2005, p.17-18).

Os autores Ketzer et al. (2017) apontam uma característica pertinente ao colocar que os sujeitos possuem a capacidade de apropria-se de identidades diferenciadas, já que o mesmo sofre influências do meio em que está inserido e pelo momento que está enfrentando. Entretanto, vale ressaltar que a cultura nacional do refugiado/imigrante é a principal origem de sua identidade. $O$ racismo que estes sujeitos enfrentam não ocorrem apenas nas ruas, mas também dentro de órgãos governamentais e principalmente no contexto do trabalho, discriminação essa que em sua maioria ocorre em função da etnia e religião (KETZER et al., 2017).

A dinâmica de como se dá a inserção dos imigrantes/refugiados no mercado de trabalho brasileiro, bem como os aspectos psicossociais que a situação resulta, são aspectos importantes a serem pontuados nesta pesquisa. $O$ aumento da imigração de populações caribenhas e da América Latina para o Brasil tem aumentado e este fenômeno foi bem citado por alguns autores. Bem como a receptividade no mercado de trabalho brasileiro. Segundo Medeiros et al. (2019) existe uma relação decrescente quando compara salários a gênero, escolaridade, pais de origem e cor.

Ainda de acordo com os autores "[...] O mercado de trabalho não demonstra estar receptivo aos estrangeiros de determinada origem e possuindo determinadas características. " (MEDEIROS et al., 2019, p.30). 
$\mathrm{Na}$ literatura foi encontrada uma presença relevante de citações sobre povos haitiano e bolivianos que buscam o Brasil como destino. Cavalcanti, Oliveira e Tonhati (2014) corrobora com esta ideia ao diferenciar as diferenças entre fenômenos migratórios anteriores ocorridos no Brasil com os da atualidade. Os autores ainda complementam que grande parte dos imigrantes formais e que possuem vínculos trabalhistas são do sexo masculino (CAVALCANTI; OLIVIRA e TONHATI, 2014).

Embora relate o aumento expressivo do público feminino no fenômeno migratório, os autores apontam que ao relacionar a mulher com a legalidade e posição no mercado de trabalho, ela está em campo de atuação assistencialista como babás, serviços de limpeza e cuidados com idosos, em grande parte no mercado informal. Sobre isso, Cavalcanti, Oliveira e Tonhati (2014, p. 14) discorrem que "[...] Muitas dessas atividades são marcadas pela precariedade e pela ausência de vínculo formal no mercado de trabalho".

Sendo assim, ao falar das dificuldades que um imigrante e/ou refugiado enfrentam durante o processo de inserção no mercado de trabalho, vale refletir sobre como essas ações impactam na saúde destes sujeitos e, como se dá o acolhimento dos mesmos, por parte dos programas e dos funcionários da saúde, no Brasil.

Martins-Borges (2015) traz em seu trabalho uma reflexão importante sobre aspectos da saúde mental, ao colocar a relação que existe "entre cultura, mundo psíquico e saúde mental" (p.153). A autora aponta que o mundo interno, que ela denomina como mundo psíquico, pode transferir informações ao mundo externo, que seria a cultura, já que ambas possuem a mesma linguagem. Entende-se a cultura como um espaço que possibilita a construção da linguagem e também o desenvolvimento psíquico (MARTINS-BORGES, 2015).

Desta forma, como apontam Martins-Borges (2015), a mudança de um lugar para o outro não é algo simples, mas quando esse deslocamento é forçado, pode promover a sensação de percas, já que não houve tempo para despedida e elaboração. A mudança de forma brusca e inesperada, pode provocar o sentimento de fracasso e de saudade. Sobre o refugiado, ele pode ser visto como o sujeito que está buscando 
se projetar em seu novo local de morada na maior parte do tempo, mas que acaba sendo abatido por sentimentos que remetem ao passado, de seu país de origem (MARTINS-BORGES, 2015).

Os autores Martin, Goldberg e Silveira (2018), trazem em sua pesquisa sobre "Imigração, refúgio e saúde: perspectivas de análise sociocultural”, um exemplo pertinente que ocorre na cidade de São Paulo, quando o assunto é a inclusão de imigrantes e refugiados no Sistema Único de Saúde (SUS). A cidade que realizou a contratação de novos agentes comunitários provenientes dos grupos de imigrantes. Unidades Básicas de Saúde (UBS) e estratégia Saúde da Família, vem auxiliando e mostrando o aumento da inclusão de imigrantes e refugiados no SUS (MARTIN; GOLDBERG e SILVEIRA, 2018).

Martin; Goldberg e Silveira (2018), ao citarem Malkki (1996) e Sargent e Larchanché (2011), discorrem sobre algumas especificidades necessárias para intervenção dentro dos grupos de refugiados ou imigrantes, pessoas essas que, muitas vezes, acabam sendo vistas como pessoas fugitivas, que só chegaram para trazer problemas econômicos e sociais. Entretanto, vale ressaltar que estes sujeitos, seja ele refugiado ou imigrante, são pessoas que nasceram e cresceram em um país que tem sua própria cultura, idioma, vestimenta, conduta, educação, dentre outros. Sendo assim, apesar de toda a sua complexidade, a cultura daqueles que vem de fora precisa ser considerada e respeitada, o que acaba se tornando um desafio no campo da saúde, pela falta de conhecimento (MARTIN; GOLDBERG e SILVEIRA, 2018).

Diante dos desafios, Martin; Goldberg e Silveira (2018) apontam que o profissional da saúde, seja ele de qual área for, precisa estar aberto para realizar essa troca com o refugiado ou com o imigrante, apresentando para esses sujeitos as diferenças de costumes, como uma forma de acolhimento, um acalento ao sofrimento, muitas vezes provocado pelos desafios de inserção dessa nova cultura.

Diante de tudo que foi levantado anteriormente, entende-se que a vida daqueles que buscam um novo espaço de morada para recomeçar, é marcada por muito sofrimento e desconforto. Mudar de um país para o outro, muitas vezes significa começar do zero, 
a busca por uma nova forma de subsistência em meio ao desconhecido torna o ambiente de trabalho um grande desafio.

\section{ANÁLISE E RESULTADOS}

Tendo como base os objetivos que foram apresentados no início deste trabalho, foram realizado, uma busca no campo das literaturas, materiais de alguns autores que discutissem sobre a inserção de imigrantes e refugiados no campo de trabalho brasileiro, e os impactos que a mudança de um país para o outro pode provocar nos processos de saúde e doença dos mesmos e também, a busca por definições de palavras chaves que fizeram toda a diferença na construção do trabalho.

Antes de adentrar na busca sobre a inserção de imigrantes e refugiados no mercado de trabalho brasileiro, optou-se por realizar uma busca que pudesse auxiliar nas definições das palavras "imigrante" e "refúgio/refugiado", pois com a pesquisa bibliográfica, sentiu-se a necessidade de buscar as definições das mesmas, bem como a busca das palavras "emigrante" e "migrante" também foram pesquisadas. Foi decidido utilizar o dicionário para trazer essas definições, por conta das dificuldades em encontrar materiais nas bases de dados científicas.

A princípio o objetivo foi de buscar materiais que pudessem demonstrar a eficiência das políticas públicas no acolhimento de refugiados e imigrantes. Para isso, foram encontrados alguns materiais, dentre eles, Martin, Goldberg e Silveira (2018) que apresentam em seu material como exemplo, a cidade de São Paulo, a qual é considerada a cidade que mais recebe imigrantes e refugiados no país, e que por isso conta com uma lei municipal para tentar acolher os sujeitos naquela região.

Em relação a busca de materiais que discorressem sobre os motivos que levam os sujeitos a se deslocarem de seu país de origem, mais especificamente tendo o Brasil como destino de morada, foi encontrado uma diversidade de artigos com informações muito semelhantes. Gondim et al. (2013) levantam aspectos como a violência, fome e perseguições políticas como causas dessas mudanças. Os autores Truzzi e Monsma (2018) colocam o Brasil como sendo um destino de morada, por ser considerado um 
local de diversidades culturais, raciais que demonstra acolhimento, e também por não ser considerado um país violento em termos de guerras civis.

Quando se propõe debater acerca dos motivos que levam imigrantes a escolher o Brasil como destino, nota-se a necessidade de pesquisar números que mostrem um retrato mais aproximado do quantitativo de pessoas que pediram refúgio ou imigraram para o Brasil. Para isso, foi pesquisado no site da Polícia Federal dados de 2017 a 2019 e que se aproximam mais da realidade.

Com base nestes dados, é possível observar na figura 1, que ao se ter como referência a América Latina como origem, nota-se a predominância de imigrantes oriundos da Bolívia.

Gráfico 1: Total de Imigrantes que entraram no Brasil, por país da América Latina (POLÍCIA FEDERAL, 2020).

\section{TDTLL DE MERANES POR PÁS}

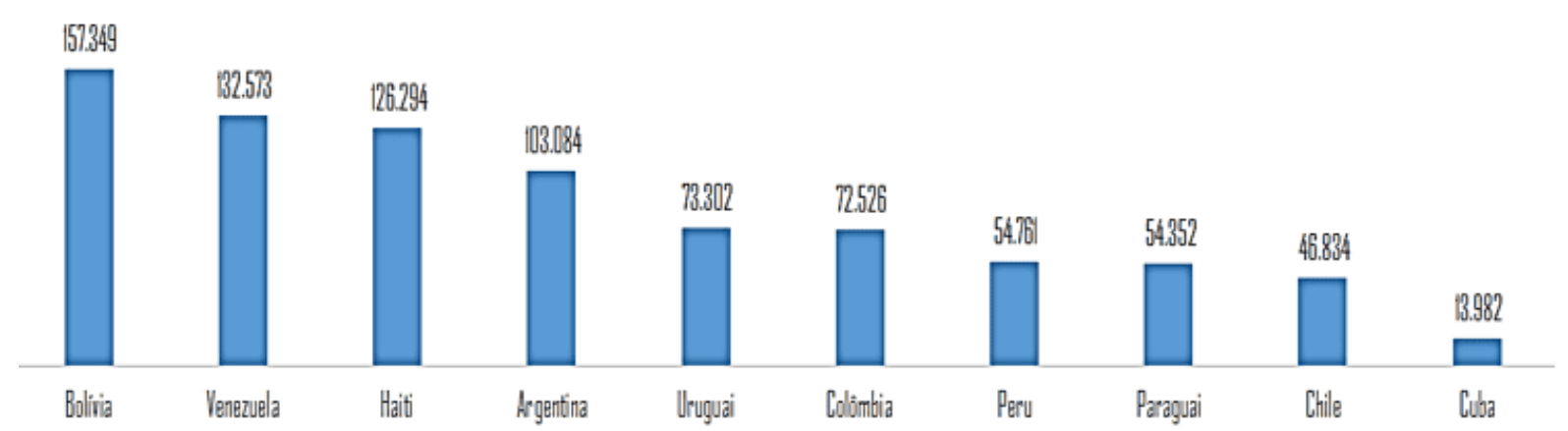

Quanto aos dados referentes aos refugiados nota-se um quantitativo maior de solicitações formais vindos da Venezuela e Haiti conforme dados da Polícia Federal e demonstrados na figura 2 abaixo. 
Gráfico 2: Total de refugiados ativos no Brasil (POLÍCIA FEDERAL, 2020).

\author{
TOTAL DE REFUGAADDS
}

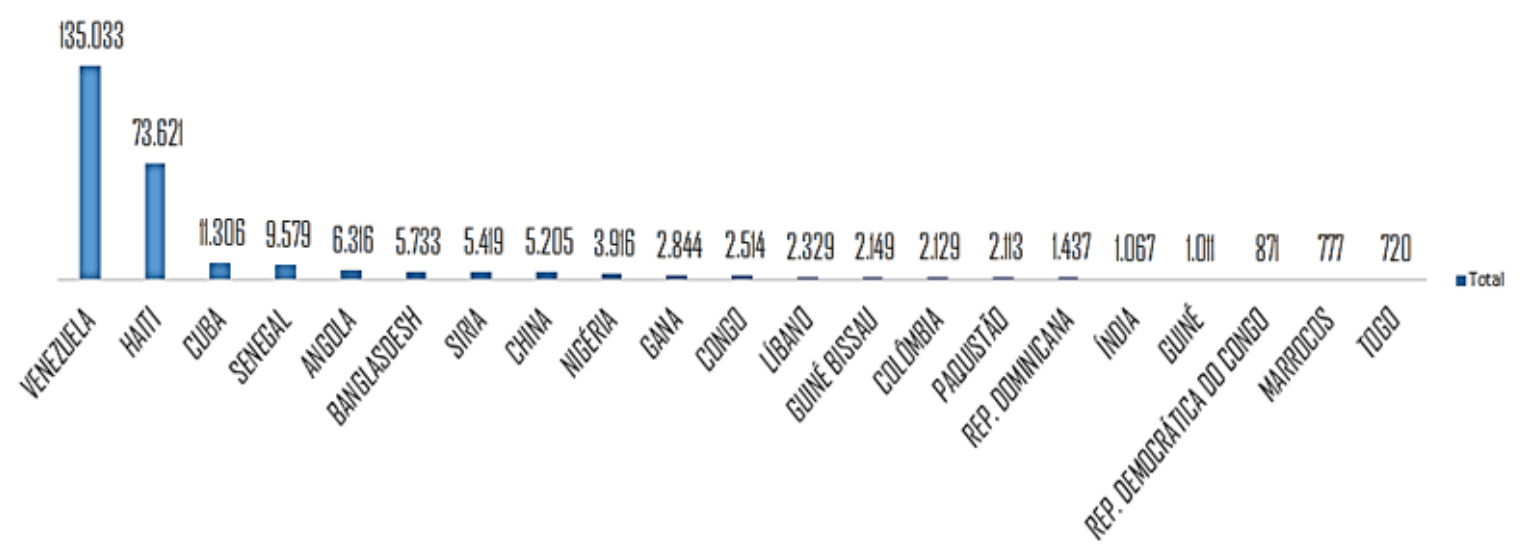

É possível observar uma predominância de refugiados mulheres quando comparado o gênero conforme figura 3.

Gráfico 3: Refugiados no Brasil por gênero (POLÍCIA FEDERAL, 2020).

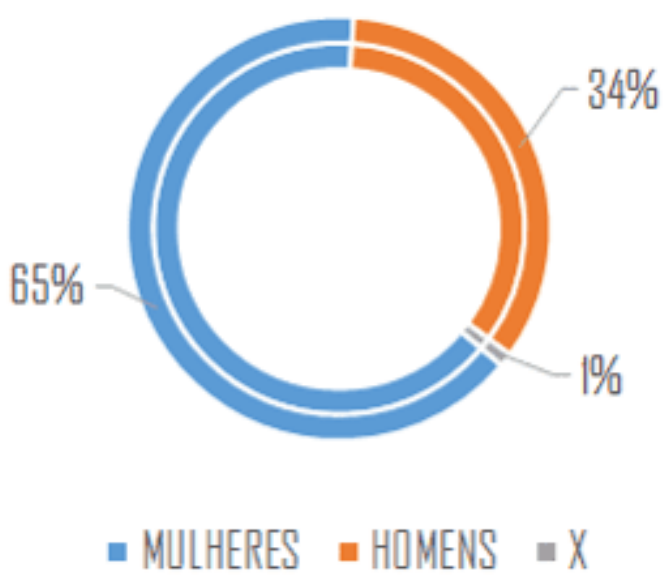

Ao adentrar no tema sobre inserção no mercado de trabalho, os autores Cavalcanti; Oliveira e Tonhati (2014) apontam que uma parcela significativa de imigrantes do sexo masculino, possuem vínculos empregatícios formais no mercado de trabalho, enquanto as mulheres ocupam espaços do trabalho informal, as quais em muitos momentos acabam sendo submetidas a precariedade. Diante desses dados, entende- 
se que há uma necessidade de compreensão maior sobre esses dados, entender o que leva as mulheres a ocuparem mais vagas de trabalho informal do que os homens.

Durante a construção do trabalho, buscou-se nas produções científicas, materiais que pudessem trazer dados sobre o processo de adoecimento dos refugiados e imigrantes no mercado de trabalho e formas de acolhimentos que são adotadas nas localidades em que se recebem os mesmos. No decorrer da leitura, entendeu-se que o sofrimento é inevitável, já que o sujeito se encontra numa posição em que é necessário lidar com o desconhecido e com a crise de pertencimento.

Para essa reflexão, foi utilizada a autora Martins-Borges (2015), que ao discorrer sobre os sentimentos despertados diante da mudança de localidade, aponta que a cultura tem a capacidade de promover o desenvolvimento psíquico e de linguagem, e que o distanciamento dessa cultura pode provocar os sentimentos de fracasso e de saudade.

Por outro lado, nota-se que tanto o adoecimento físico e o mental acabam contando com uma política pública não muito eficiente, mas também se entende que os próprios brasileiros não podem contar com um suporte de qualidade. Isso nos mostra o quanto ainda é necessário melhorar os suportes de atendimento e acolhimento na saúde e, quando se trata de refugiados ou imigrantes, é necessário mudar a forma discriminatória como se olham para estes sujeitos, que assim como qualquer outro ser humano, precisam ser vistos como tal.

\section{CONCLUSÃO}

Levando em consideração os fatos apresentados, o presente trabalho apresenta inicialmente uma problemática acerca da motivação dos imigrantes e refugiados em procurar o Brasil como destino e como se dá a inserção deste público no mercado de trabalho brasileiro. Para isso, foi realizada uma revisão bibliográfica para a coleta de dados. 
O objetivo principal foi entender a motivação na escolha do Brasil como destino final e como se desenvolvia a dinâmica de entrada no mercado de trabalho, bem como, os impactos causados nesse processo de adaptação. Pode-se dizer que objetivo foi alcançado, já que em alguns materiais, foram encontradas informações que apontavam possíveis motivos que torna o Brasil como um espaço de morada para refugiados e imigrantes.

A construção do artigo torna-se relevante pois, durante o processo de leitura e construção, ficou notório a importância de se explorar esta linha de pesquisa, tanto no âmbito das Políticas Públicas, quanto no meio da Psicologia Organizacional. Há uma necessidade de se debruçar sobre essa problemática, para que seja elaborado um construto que promova um cenário para debates de melhorias de acolhimento, elaboração de propostas para melhora da qualidade de vida e desenvolvimento social e profissional destes imigrantes e refugiados.

\section{REFERÊNCIAS}

BAUMAN, Zygmunt. Identidade: entrevista a Benedetto Vecchi. Rio de Janeiro : J. Zahar, 2005.

CARNEIRO, Cynthia Soares. Migrações internacionais e precarização do trabalho: o contexto global, os acordos de residência do Mercosul e os imigrantes sul-americanos no Brasil. Argumenta Journal Law, Jacarezinho - PR, n. 26, p. 337-376, ago. 2017. ISSN 2317-3882. Disponível em: <http://seer.uenp.edu.br/index.php/argumenta/article/view/749>. Acesso em: 29 fev. 2020.

CAVALCANTI, Leonardo; OLIVEIRA, Antonio Tadeu; TONHATI, Tânia (Orgs.) A Inserção dos Imigrantes no Mercado de Trabalho Brasileiro. Brasília: Cadernos do Observatório das Migrações Internacionais, 2014.

CERVO, Amado Luiz; BERVIAN, Pedro Alcino; DA SILVA, Roberto. Metodologia Científica: 6.ed.São Paulo: Person Prentice Hall, 2007. 
CONARE. Ministério da Justiça e Segurança Pública: Governo Federal. 2019. Disponível em: < https://www.justica.gov.br/seus-direitos/refugio/conare > Acesso em: 17 Mar, 2020.

COSTA, Antônio Albuquerque da; FARIAS, Paulo Sérgio Cunha. Formação Territorial do Brasil. Campina Grande: EdUEP, 2009.

ETCHEVERRY, Daniel. A atuação dos mediadores da promoção da cidadania e a problemática da visibilidade do fenômeno migratório. In: JARDIM, D. F. e LÓPEZ, L. C., orgs. Políticas da diversidade: (in)visibilidades, pluralidade e cidadania em uma perspectiva antropológica [online]. Porto Alegre: Editora da UFRGS, 2013. Práticas de justiça e diversidade cultural series, p.(59)-(72). ISBN 978-85-386-03856. Disponível em: <http://books.scielo.org/id/sny5t/epub/jardim9788538603856.epub>. Acesso em 26 Abr. 2020.

GIL, Antônio Carlos. Como elaborar projetos de pesquisa. 3.ed. São Paulo: Atlas, 2010.

GONDIM, Sônia Maria Guedes et al. Imigração e Trabalho: Um Estudo Sobre Identidade Social, Emoções e Discriminação Contra Estrangeiros. Psicol. pesq. [online]. 2013, vol.7, n.2, pp. 151-163. Dez. 2013. Disponível em:< http://pepsic.bvsalud.org/scielo.php?script=sci_arttext\&pid=S198212472013000200003\&lng=pt\&nrm=iso ISSN 1982-1247>. Acesso em: 26 Abr. 2020.

HOUAISS, Antônio; VILLAR, Mauro de Salles. Minidicionário Houaiss da língua portuguesa. Rio de Janeiro: Objetiva, 2010.

KETZER, Lisiane Selaimen Heemann, et al. Imigração, identidade e multiculturalismo nas organizações brasileiras. Interações (Campo Grande). Campo Grande, v. 19, n. 3, p. 679-696, Set., 2018 . Disponível em: $<$ http://www.scielo.br/scielo.php?script=sci_arttext\&pid=S151870122018000300679\&Ing=en\&nrm=iso>. Acesso em: 28 Mar, 2020. 
MARTINS-BORGES, Lucienne. Migração involuntária como fator de risco à saúde mental. REMHU, Rev. Interdiscip. Mobil. Hum., Brasília, v. 21, n. 40, p. 151-162, June 2013 . Disponível em: $<$ http://www.scielo.br/scielo.php?script=sci_arttext\&pid=S198085852013000100009\&Ing=en\&nrm=iso>. Acesso em: 07 Abr 2020.

MARTIN, Denise; GOLDBERG, Alejandro; SILVEIRA, Cássio. Imigração, refúgio e saúde: perspectivas de análise sociocultural. Saude soc., São Paulo, v. 27, n. 1, p. 26-36. Jan. 2018.2 Disponível em: <http://www.scielo.br/scielo.php?script=sci_arttext\&pid=S010412902018000100026\&Ing=en\&nrm=iso>. Acesso em 29 Fev. 2020.

MEDEIROS, Marcelo de Almeida et al. Fronteiras de Estados emergentes: migração, cidadania pós-nacional e trabalhadores latino-americanos no Brasil,. Isso. Bras. Ciênc. Polít., Brasília , n. 30, p. 77-112, Dec. 2019. Disponível em: $<$ http://www.scielo.br/scielo.php?script=sci_arttext\&pid=S010333522019000300077\&lng=en\&nrm=iso>. Acesso em: 29 Mar, 2020.

MOREIRA, Julia Bertino. Redemocratização e direitos humanos: a política para refugiados no Brasil. Rev. bras. polít. int., Brasília , v. 53, n. 1, p. 111-129, July 2010 . Disponível em: <http://www.scielo.br/scielo.php?script=sci_arttext\&pid=S003473292010000100006\&lng=en\&nrm=iso >. Acesso em: 02 Mar. 2020.

OLIVEIRA, Silvio Luiz. Tratado de Metodologia Científica: 1.ed. São Paulo: Pioneira, 1997.

POLÍCIA FEDERAL. Ministério da Justiça e Segurança Pública: Imigração. Abr 2020. Disponível em: < http://www.pf.gov.br/servicos-pf/imigracao/estatisticas >. Acesso em: 27 Abr. 2020.

TRUZZI, Oswaldo; MONSMA, Karl. Sociologia das migrações: entre a compreensão do passado e os desafios do presente. Sociologias. Porto Alegre, v. 20, n. 49, p. 18 23 ,

Dez. 2018.

Disponível

em: 
$<$ http://www.scielo.br/scielo.php?script=sci_arttext\&pid=S1517-

45222018000300018\&Ing=en\&nrm=iso>. Acesso em: 28 Mar 2020.

Enviado: Maio, 2020.

Aprovado: Novembro, 2020. 